\title{
Silver deposition in the cervix after application of silver nitrate as a cauterising agent
}

\author{
D G LOWE, D A LEVISON, P R CROCKER, J H SHEPHERD* \\ From the Departments of Histopathology and *Gynaecology, St Bartholomew's Hospital, London
}

SUMMARY Large amounts of metallic silver pigment were found in 10 cervical biopsy specimens taken for the histological grading of cervical intraepithelial neoplasia (CIN). The assessment of CIN was made much harder because the pigment obscured the morphological detail of the epithelial cells, and in some it was very difficult to determine whether koilocytosis or CIN I was present. The silver can easily be removed by a simple chemical method.

In several biopsy specimens of cervical tissues taken for the histological grading of cervical intraepithelial neoplasia (CIN), variable amounts of granular brown pigment were found. The gynaecologists who had performed the biopsies were unable to suggest a reason for the pigment deposition-the only common factor that they could identify was that iodine solution had been applied to all of the cervices before biopsy.

Assessment of the epithelial aspects of the biopsy was difficult as the pigment overlay the epithelial cells (fig 1). It was decided to analyse the material by $x$-ray energy dispersive spectroscopy as an initial step towards its removal from tissue sections.

\section{Material and methods}

Routinely processed haematoxylin and eosin stained paraffin wax sections from 10 cervical biopsy specimens that were found to have large amounts of brown granular pigment in and between the epithelial cells of the squamous ectocervical mucosa were examined by $x$-ray energy dispersive spectroscopy. The 10 cases were collected from the routine gynaecological material over a period of five weeks, and the patients' ages ranged from 25-38 years (mean 29 years).

The methods used have been described in detail elsewhere ${ }^{2}$ but briefly, comprise removal of the coverslip, coating of the section with carbon in a Nanotech CC2 carbon coater, and examination of the section in a Jeol 35 CF scanning electron microscope equipped with a backscattered electron detector, a Kevex Unispec System $7000 x$-ray energy dispersive spectroscopy unit, and an Apple Microplus data

Accepted for publication 17 March 1988 processor. All specimens were examined at $15 \mathrm{KV}$ for periods of 100 seconds.

In view of the spectroscopy findings, removal of the

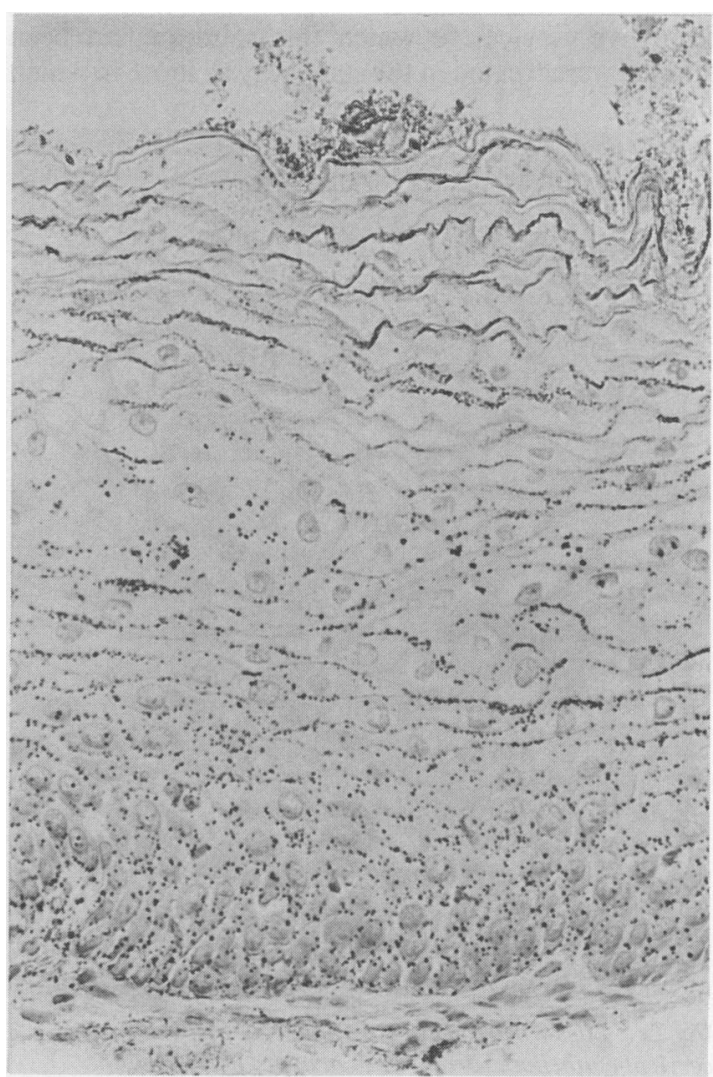

Fig 1 Granular silver deposition throughout mucosa makes assessment of CIN very difficult. (Haematoxylin and eosin.) 
pigment was attempted with a $4: 1$ mixture $5 \%$ aqueous solution of sodium thiosulphate and $0.5 \%$ aqueous potassium ferricyanide, in which the sections were immersed for five minutes. ${ }^{3}$ The sections were then stained with haematoxylin and eosin and mounted routinely.

Cautery with a silver nitrate pencil (Avoca Pharmaceutical Products Ltd, UK, product licence number 4286/0004) was applied to fresh cervical tissue removed at hysterectomy for uterine leiomyomas; there was no clinical indication of cervical disease, and histological sections of the treated areas were examined after removal of the silver deposit to confirm that no lesions were present. The pencils were held in contact with the ectocervical epithelium for periods of five seconds, 10 seconds, 30 seconds, one minute, two minutes and five minutes. The specimens were then washed in formol saline and fixed in formalin. Tissue for transmission electron microscopy was taken from the specimen in contact with a silver nitrate pencil for 30 seconds.

A $3 \%$ solution of iodine in potassium iodide is used routinely at this hospital to delineate abnormal epithelium (modified Schiller test). ${ }^{46}$ Biopsy specimens from five cervices to which this solution had been applied were treated in the same way as those in which brown pigment was found, to investigate whether this might be related to the brown deposit.

\section{Results}

X-RAY ENERGY DISPERSIVE SPECTROSCOPY (XES)

Analysis of all of the cervical biopsy specimens showed that the predominant element present in the brown pigment was silver. Chlorine was also present and in some cases there were traces of iodine (figs $2 a$ and $b$ ). XES of one of the silver nitrate cautery sticks in routine use in the gynaecology clinics showed silver, potassium, and traces of chlorine. Analysis of the cervical tissues treated in vitro with the silver nitrate stick showed only silver and chlorine in the tissues. The cervical biopsy specimens painted in vitro with iodine solution showed traces of iodine alone; no silver was present.

\section{LIGHT MICROSCOPY}

Silver deposition in cervical tissues was found histologically to consist of mid-brown to dark-brown pigment lying within and between epithelial cells (figs 1 and 3). The pigment was present in the epithelium to which silver nitrate cautery was applied, in the immediately adjacent mucosa, and in the stroma in

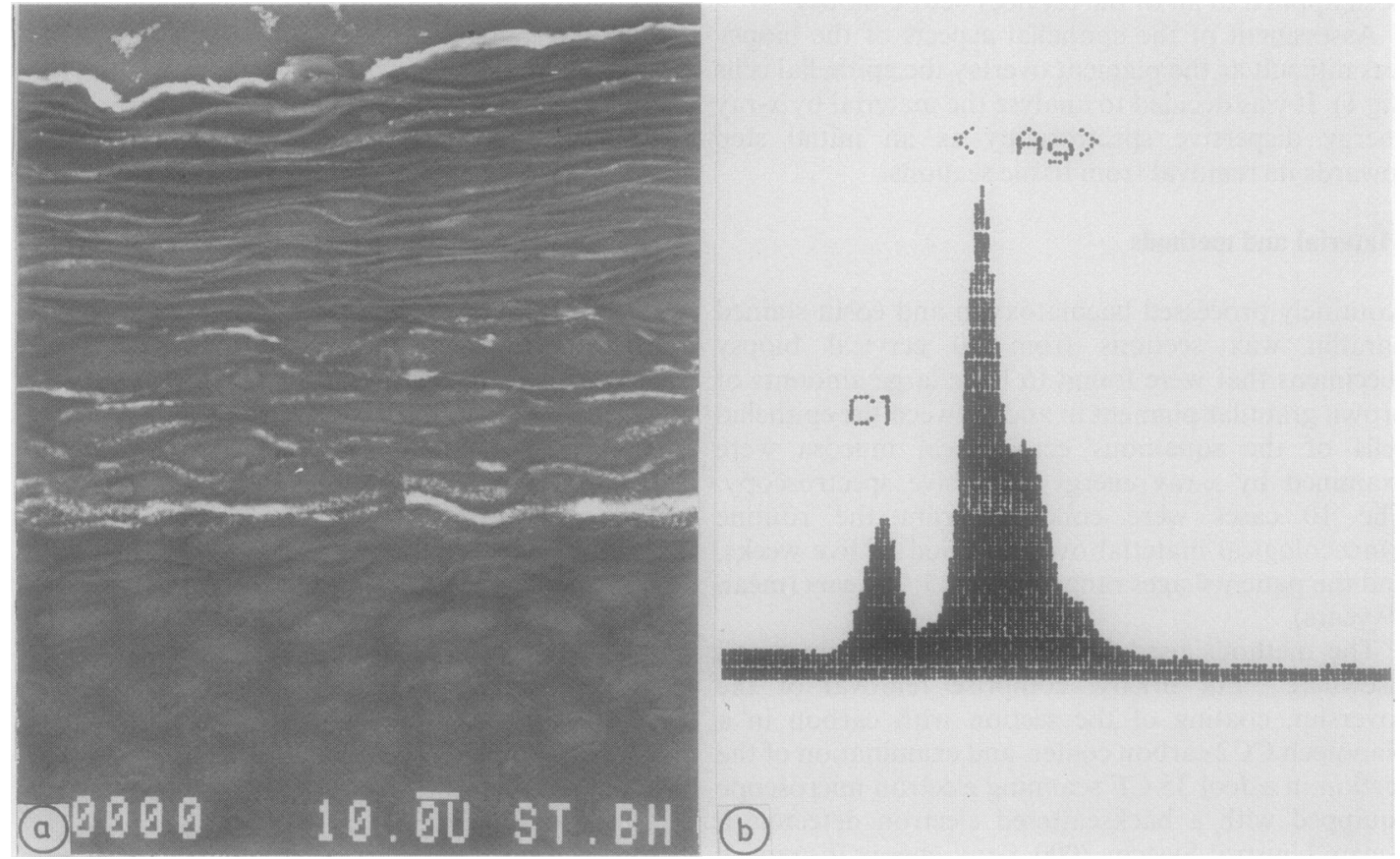

Fig 2a Backscattered electron image of silver-treated cervical epithelium. Bright lines in upper half of field correspond to dark lines of silver deposit seen on light

Fig $2 \mathrm{~b} \quad x$-ray energy dispersive spectrograph of one of the bright areas showing silver and chlorine. 


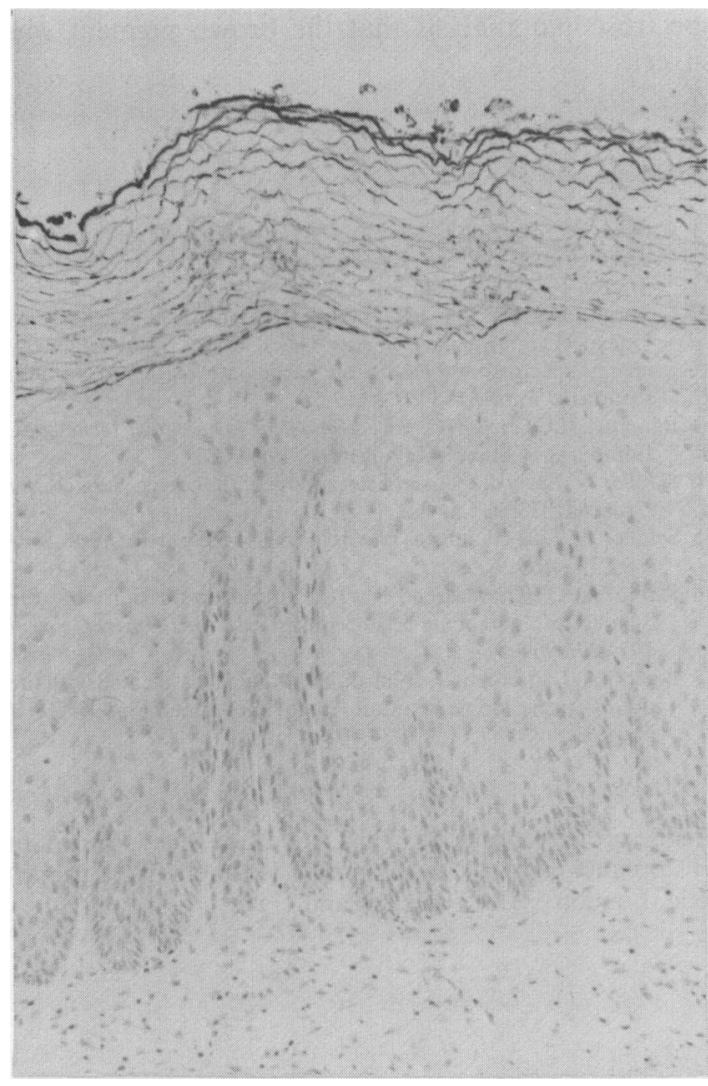

Fig 3 Silver deposition has occurred in upper levels of ectocervical epithelium and there is accumulation of pigment in a line in the intermediate cell zone. (Haematoxylin and eosin.)

some cases.

In the stratified squamous epithelium of the ectocervix of the biopsy specimens pigment was found between the superficial and intermediate zone cells, and where deposition was extensive, was present between and within parabasal and basal cells. In most cases the mucosa was spongiotic, and in some this was severe. The intercellular oedema emphasised the presence of discrete silver granules between the squamous cells.

Where diffusion of the silver had occurred through the mucosa into the underlying stroma, there was heavy deposition on the basement membrane. When silver nitrate was applied to the simple columnar epithelium of the endocervix and portio, relatively little pigment was deposited in the epithelium and more was found in the stroma below it. Deposition on the basement membrane was especially prominent below columnar epithelium. Blood vessels in the stroma showed fibrin deposition and clumping of red cells.
In the cervical specimens to which silver nitrate was applied experimentally, the level of penetration of the silver pigment corresponded to the length of time of application of the silver nitrate stick. After periods of five and ten seconds pigment was present only in the superficial layers of the mucosa; after 30 seconds pigment had reached the intermediate layers and the parabasal cells; and after two minutes the basal cells and immediately subjacent stroma were affected. The extent of deposition of silver seemed to depend simply on the rate of diffusion of silver nitrate in solution. Spongiosis was present in specimens treated with the cautery stick for one minute or longer.

Removal of the silver by sodium thiosulphate/ potassium ferricyanide solution clearly showed the underlying squamous cells. In the biopsy specimens treated for up to one minute the grade of CIN could be assessed as easily as if silver nitrate had not been applied. In the cases to which silver nitrate had been applied for two and five minutes, the severity of the spongiosis made assessment of CIN very difficult as the nucleus:cytoplasm ratio of the epithelial cells had been changed.

Neither in vivo nor in vitro application of $3 \%$ iodine solution to cervical epithelium caused any appreciable histological change. In the cases treated with both iodine solution and silver nitrate there was no apparent additive effect of the iodine on the amount of pigment deposition.

\section{TRANSMISSION ELECTRON MICROSCOPY}

Transmission electron microscopic examination of the affected tissues confirmed the light microscopical findings that most of the silver was deposited between the epithelial cells. Smaller amounts were scattered randomly in the cytoplasm of the squamous cells and had no apparent association with organelles. The severe spongiosis in places had resulted in rupture of desmosomal connections and separation of squamous cells from their neighbours, but there was no evidence of spongiotic vesicle formation.

\section{CLINICAL CORRELATION}

When the results of the spectroscopic analysis were known, the surgical pathology cases were reviewed with the clinicians. It became apparent that all of the cases containing pigment we ilmost certainly taken as second or subsequent bii iy specimens after the haemorrhage caused by the irrst biopsy had been stanched with a silver nitrate stick.

\section{Discussion}

The common practice of applying a silver nitrate stick to cervices after biopsy to stanch the haemorrhage from the biopsy site can lead to large amounts of silver 
being deposited in the epithelium and stroma of the cervix. It can also cause spongiosis of the squamous mucosa of the ectocervix. There was little chance that the spongiosis might be attributed to an inflammatory cause, as silver granules were obvious in all of the tissues with spongiosis. The degree of spongiosis in our cases was similar to that described by Benda and coworkers $^{7}$ as a result of application of strong (5\%) iodine solution to the cervix.

Silver nitrate application did not produce the cytoplasmic eosinophilia, loss of chromatin detail and poor delineation of nuclei and nucleoli described after colposcopic treatment with strong iodine solution, and there was therefore not the same risk of confusion between squamous metaplasia and dysplasia. It was interesting that the $3 \%$ iodine solution used in this study did not induce the artefactual changes found after treatment with $5 \%$ iodine solution. The pigment, on the other hand, can cause diagnostic difficulties by obscuring the detail of the underlying mucosal cells. Once it is recognised as silver, it can easily be removed by a simple thiosulphate/ferrocyanide method.

Our thanks and compliments are due to Dr G Philip of Kingston Hospital, Kingston-upon-Thames, England, who recognised without the benefit of $x$-ray spectroscopic analysis that the brown pigment was silver.

\section{References}

1 Crocker PR, Toulson E, Levison DA. Particles in paraffin sections demonstrated in the backscattered electron image (BEI). Micron 1982;13:437-46.

2 Levison DA, Procker PR, Lee G, Shepherd NA, Smith A. Unexpected inorganic elements in oral lesions: results of X-ray energy spectroscopy (XES) on particulate matter in paraffin sections. J Pathol 1984;144:119-29.

3 Bancroft JD, Cook HC, eds. Manual of histological techniques. Edinburgh: Churchill Livingstone, 1984:157.

4 Schiller W. Early diagnosis of carcinoma of the cervix. Surg Obstet Gynecol 1933;56:210-22.

5 Schiller W. Early diagnosis of carcinoma of the portio uteri. Am J Surg 1934;26:269-80.

6 Rubio CA, Thomassen P. A critical evaluation of the Schiller test in patients before conization. Am J Obstet Gynecol 1976;125:96-9.

7 Benda JA, Lamoreaux J, Johnson SR. Artifact associated with the use of strong iodine solution (Lugol's) in cone biopsies. Am J Surg Pathol 1987;11:367-74.

Requests for reprints to: Dr D G Lowe, Department of Histopathology, St Bartholomew's Hospital, West Smithfield, London ECIA 7BE, England. 